\title{
Promotion of the Hypocrellin Yield by a Co-Culture of Shiraia bambusicola (GDMCC 60438) with Arthrinium sp. AF-5 Fungus
}

\author{
Xiaoxiao Yan ${ }^{1,2}$, Yongdi Wen ${ }^{1}$, Menghua $\mathrm{Hu}^{1}{ }^{1}$, Zhenqiang $\mathrm{Wu}^{1}$ and Xiaofei Tian ${ }^{1,2, *(D)}$ \\ 1 Guangdong Key Laboratory of Fermentation \& Enzyme Engineering, School of Biology and Biological \\ Engineering, South China University of Technology, 382 East Out Loop, University Park, \\ Guangzhou 510006, China; 201921046927@mail.scut.edu.cn (X.Y.); 202020148989@mail.scut.edu.cn (Y.W.); \\ 202121050731@mail.scut.edu.cn (M.H.); btzhqwu@scut.edu.cn (Z.W.) \\ 2 Zhuhai Institute of Modern Industrial Innovation, South China University of Technology, 8 Fushan Road, \\ Fushan Industrial Park, Zhuhai 519100, China \\ * Correspondence: xtien@scut.edu.cn
}

Citation: Yan, X.; Wen, Y.; Hu, M.; Wu, Z.; Tian, $X$. Promotion of the Hypocrellin Yield by a Co-Culture of Shiraia bambusicola (GDMCC 60438) with Arthrinium sp. AF-5 Fungus. Fermentation 2021, 7, 316. https:// doi.org/10.3390/fermentation7040316

Academic Editor: Matthew L. Bochman

Received: 17 November 2021 Accepted: 9 December 2021 Published: 16 December 2021

Publisher's Note: MDPI stays neutral with regard to jurisdictional claims in published maps and institutional affiliations.

Copyright: (C) 2021 by the authors Licensee MDPI, Basel, Switzerland. This article is an open access article distributed under the terms and conditions of the Creative Commons Attribution (CC BY) license (https:// creativecommons.org/licenses/by/ $4.0 /)$.

\begin{abstract}
Hypocrellin is a natural 3,10-xylene-4,9-anthracene derivative compound that originates from the stroma of Shiraia bambusicola (S. bambusicola) and Hypocrella bambusae with excellent photobiological activities. Submerged fermentation with the mycelia of S. bambusicola is generally regarded as an ideal technology for hypocrellin production. This study developed a co-cultivation strategy for an obvious promotion of the hypocrellin yield by incubating S. bambusicola (GDMCC 60438) with the endophyte fungus Arthrinium sp. AF-5 isolated from the bamboo tissue. The results indicated that the yield of hypocrellin A (HA) reached a $66.75 \mathrm{mg} / \mathrm{g}$ carbon source after an 84-h co-cultivation of the two strains, which was a four-time increase of that by the fermentation only with the S. bambusicola. The microscope observation found that the mycelia of the two strains were intertwined with each other to form the mycelium pellets during the co-cultivation. Moreover, the mycelium pellets of the co-culture showed a contracted and slightly damaged morphology. The addition of $\mathrm{H}_{2} \mathrm{O}_{2}$ in the fermentation media could further increase the HA production by $18.31 \%$.
\end{abstract}

Keywords: hypocrellins A; S. bambusicola; endophyte fungi; mycelium pellets

\section{Introduction}

Shiraia bambusicola Henn. and Hypocrella bambusae (Berk. \& Broome) Sacc. (Ascomycetes) are pathogenic fungi of bamboo in east Asia [1-3]. As Chinese folk medicines, the stroma of the two fungi could be widely used to treat rheumatoid arthritis, tracheitis, and oxyhepatitis, etc. A variety of secondary metabolites, such as perylene quinones, anthraquinones, and polysaccharides, were isolated from the fungal stroma [4]. The hypocrellins belonging to perylene quinones generally include hypocrellin A (HA), hypocrellin B, hypocrellin C, and hypocrellin D [5-7] (Figure 1). The hypocrellins are photosensitizers with advanced photosensitive therapeutic activities against the tumor, virus, retinopathy, and human immunodeficiency virus (HIV) [8-12]. Unfortunately, the current supply of the hypocrellin source has failed to meet the increasing demand because of the limited productivity of the natural fungal stroma. Although the metabolic pathways' biological synthesis of the hypocrellins is still unclear, submerged fermentation with S. bambusicola has excellent application prospects in producing hypocrellins [13]. In recent years, various methods have been developed to increase the yield of the hypocrellins through fermentation, such as genetic modification and mutagenesis of the strains, optimization of media and cultivation conditions, and chemical and physical induction [12-15]. Through fermentation, the yield of the hypocrellins reached $90-8700 \mathrm{mg} / \mathrm{L}[14,15]$. 


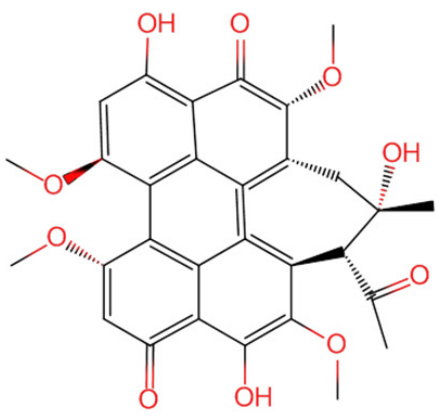

Hypocrellin A (HA)

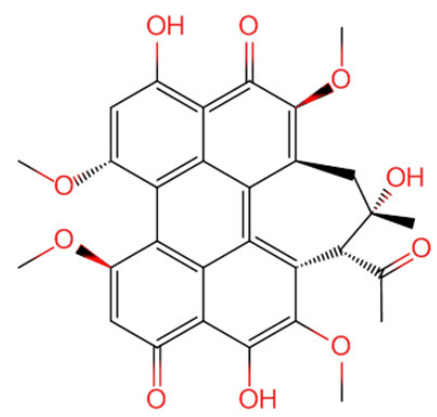

Hypocrellin C (HC)

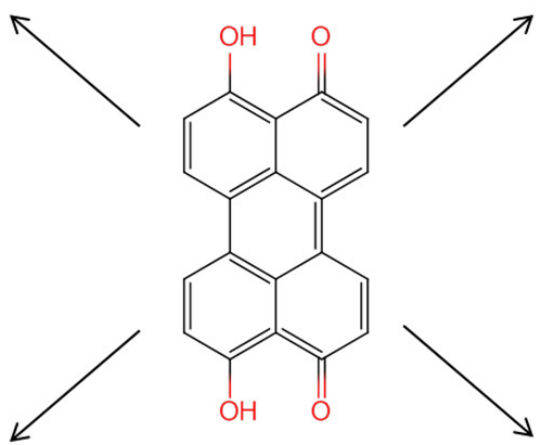

Perylene quinones core<smiles></smiles>

Hypocrellin B (HB)

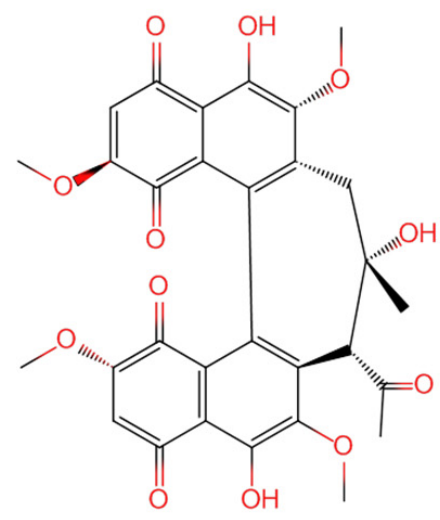

Hypocrellin D (HD)

Figure 1. The chemical structure of the perylene quinones core and hypocrellins.

Fungi can elaborate the various enzymes for synthesizing secondary metabolites, most of which are critical natural sources of medicines with broad application prospects. Therefore, there has been a strong interest in scientific research and the industrialization of fungal metabolite production [16-20]. However, in the natural condition, a single strain usually failed to initiate the biological synthesis of the compounds [16,21]. The generation of secondary metabolites usually requires specific chemical and physical signal stimulation. In nature, microorganisms interact with others through competition, symbiosis, cooperation, antagonism, or parasitism [22]. The fungal strains' growth and metabolism could be influenced by the direct contact of multiple microbial cells or the communication of specific signal substances in the mixed colonies [23]. Artificial simulation of the signals encountered under natural conditions is one of the effective strategies for increasing the yield of secondary metabolites, such as the addition of elicitors and microbial co-culture [24-28]. The microbial co-culture method has become an important approach to improve the yield of products, produce new metabolites, and promote the activity of products through fermentation [29-31]. It has been widely applied in food, industry, agriculture, medicine, and pro-environment fields [32-34]. For instance, the transcription of AFP that codes a strong alkaline polypeptide with antifungal activity in Aspergillus giganteus could be triggered to start by Fusarium oxysporum [35]. The yield of Enniatin A1 with antibacterial activity was increased by 78 times by the co-culture of Fusarium tricinctum and Bacillus subtilis [36]. When the Saccharomyces cerevisiae and Aspergillus oryzae were simultaneously incubated with Monascus sp., the yield of Monascus pigments could be increased by 30 to 
40 times [37]. Ma et al. firstly reported that the Pseudomonas related to the fruiting bodies of the $S$. bambusicola could stimulate the HA accumulation of $S$. bambusicola, resulting in an HA yield of $225.34 \mathrm{mg} / \mathrm{L}$, which was about 3.25 times that of the single culture [38]. Rather than bacteria, fungi that produce distinct metabolites have great potential and should be worth studying in the co-culture with S. bambusicola for improving the yield of hypocrellins.

In this study, 17 endophytic fungi isolated from the bamboo branches where the stroma of $S$. bambusicola grows were submitted to the co-culture with $S$. bambusicola (GDMCC 60438) through submerged fermentation. The strain AF-5, which showed the most positive effect on promoting the HA production, was selected. The effects of the inoculation dosage and co-culture time on the HA yield were also investigated. The modifications of the morphological features of the mycelium pellets by the co-culture were also examined.

\section{Materials and Methods}

\subsection{Preparation of the Endophytic Fungi Inculumn for Co-Culture}

The 17 endophytic fungi strains (AF-1, AF-2, AF-3, AF-4, AF-5, AF-6, AF-7, BF-1, BF-2, BF-3, BF-4, BF-5, BF-6, BF-7, BF-8, BF-9, BF-10) isolated from Pleioblastus amarus (Keng) Keng (Hangzhou, Zhejiang, China) were cultivated at $28^{\circ} \mathrm{C}$ on potato dextrose agar (PDA, Guangdong Huankai Microbial Technology Co., Ltd., Guangzhou, China) medium for 7 days. The mycelia with the PDA medium were cut into $1 \times 1 \mathrm{~cm}$ blocks and then transferred into a $250-\mathrm{mL}$ flask containing $50 \mathrm{~mL}$ potato dextrose broth (PDB, Guangdong Huankai Microbial Technology Co., Ltd., Guangzhou, China) media. After the cultivation performed at $28^{\circ} \mathrm{C}$ for $48-60 \mathrm{~h}$, the broth was centrifuged at $9000 \mathrm{rpm}$ for $10 \mathrm{~min}$ to collect the fresh fungal mycelium (FFM) and fungus suspension (FS) of the endophytic fungi. After the collected FFM was freeze-dried for $10 \mathrm{~h}$, fungal crude polysaccharide (FCP) of endophytic fungi were extracted by hot-water extraction. The proteins were removed from the FFM by the Sevag method [39].

\subsection{HA Fermentation by Co-Culture of S. bambusicola and Endophytic Fungi}

The S. bambusicola (GDMCC 60438) was cultivated on PDA and at $28^{\circ} \mathrm{C}$ for 5 days. The plate was washed with $8 \mathrm{~mL}$ of sterile $\mathrm{H}_{2} \mathrm{O}$ containing $2 \%(w / w)$ ) Tween 80 (Damao chemical reagent factory, Tianjin, China). The suspension was incubated at $28^{\circ} \mathrm{C}$ at $150 \mathrm{rpm}$ in a $250-\mathrm{mL}$ flask containing $50 \mathrm{~mL}$ PDB media. After $48-60 \mathrm{~h}$, the prepared seed inoculum was adjusted to $0.6 \mathrm{~g} / \mathrm{mL}$ and submitted into a fermentation medium containing $10 \mathrm{~g} / \mathrm{L}$ glycerol (Macklin Inc., Shanghai, China), $4 \mathrm{~g} / \mathrm{L}$ potato extract (Yuanye Biotechnology Co., Ltd., Shanghai, China), and 12 g/L beef extract (Guangdong Huankai Microbial Technology Co., Ltd., Guangzhou, China) with a dosage of $10 \%(v / v)$. The fermentation for the hypocrellins only with $S$. bambusicola inoculum was conducted for $72 \mathrm{~h}$ at $28{ }^{\circ} \mathrm{C}$ and $150 \mathrm{rpm}$. After a 24-h fermentation with the $S$. bambusicola inoculum in a $250-\mathrm{mL}$ flask containing $50 \mathrm{~mL}$ fermentation media, the FFM, FS, and FCP of the endophytic fungi were separately added into the broth at the dosages of $0.06 \mathrm{~g}$ fresh weight $(\mathrm{FW}) / \mathrm{mL}, 10 \%$ and $0.06 \mathrm{~g} / \mathrm{mL}$ to start the co-cultivation, respectively. The co-cultivation with different inoculation substrates was conducted for $72 \mathrm{~h}$. Fermentation of the HA only with the $S$. bambusicola (GDMCC 60438) was set as the control.

\subsection{Strain Identification}

The extraction of the DNA from the AF-5 strain was conducted by the CTAB method [40]. The mycelium of the strain was mixed with $500 \mu \mathrm{L}$ CTAB buffer and ground with a plastic rod. After incubated at $65^{\circ} \mathrm{C}$ for $1 \mathrm{~h}$, the mixture was centrifuged at 12,000 rpm for $10 \mathrm{~min}$. The collected supernatant was extracted with saturated phenol and chloroform. The DNA was precipitated with absolute ethanol. The DNA was air-dried and dissolved in $100 \mu \mathrm{L}$ TE buffer (Sangon Biotech, Shanghai, China) before use. The internal transcribed spacer (ITS) sequences were amplified using the ITS5 (GGAAGTAAAAGTCGTAACAAGG) and ITS4 (TCCTCCGCTTATTGATATGC) primers [41]. The PCR products were detected by 
1\% gel electrophoresis and then sequenced by Sangon Biotech Co., Ltd. (Shanghai, China). The BLAST was used to compare the similarity of the ITS sequence of the AF- 5 strain with reported sequences in the Genbank (https:/ / www.ncbi.nlm.nih.gov/, the link was last accessed on 1 June 2020). The Clustalx 1.81 was used to compare multiple sequences, and the phylogenetic tree was constructed by the MEGA-X.

\subsection{The Effect of Cultivition Conditions on the HA Yields with the S. bambusicola (GDMCC 60438) and the AF-5 Strain}

The effect of inoculum time, dosage of the endophytic fungi, and co-culture time on the HA yields were studied. The experimental levels of inoculum time were 0, 12, 24, 36, and $48 \mathrm{~h}$ after the start of the fermentation. The inoculum volumes of $0.02,0.06,0.1$, and $0.14 \mathrm{~g} \mathrm{FW} / \mathrm{mL}$ and the co-cultivation times of 24, 36, 48, 60, 72, 84, 96, and $108 \mathrm{~h}$ were applied. The activity of the $\mathrm{H}_{2} \mathrm{O}_{2}(30 \%, w / w$, Sinopharm Co., Ltd., Beijing, China) on the promotion of HA yield through co-cultivation was explored; $\mathrm{H}_{2} \mathrm{O}_{2}$ solution was added into the fermentation broth along with inoculation of the endophytic fungi. The concentrations of $\mathrm{H}_{2} \mathrm{O}_{2}$ in the broth were $0,0.5,1,5$, and $10 \mathrm{mM}$.

\subsection{Morphological Observation of the Mycellium Pellets from the Co-Culture}

Morphology of mycelium pellets and mycelium were observed by stereomicroscope and scanning electron microscope (SEM), respectively. The mycelium after fermentation for $12,24,36,48$, and $60 \mathrm{~h}$ were washed with $0.1 \mathrm{M}$ phosphate buffer saline solution (PBS). The mycelium pellets were observed by a CX41 stereomicroscope (Olympus Corporation, Tokyo, Japan) after suspending in the cell culture dish containing 0.1M PBS. The Image-Pro Plus 6.0 (Media Cybernetics, Inc., Silver Spring, MD, USA) was used to measure mycelium pellets' diameter. The washed mycelium was mixed with $4 \%$ glutaraldehyde solution at $4{ }^{\circ} \mathrm{C}$ for $4 \mathrm{~h}$. After centrifugated at $8000 \mathrm{rpm}$ for $5 \mathrm{~min}$, the mycelium was collected and washed using 0.1M PBS. The mycelium was dried and coated with gold by an EM SCD500 high vacuum sputter coater (Leica microsystems, Wetzlar, Germany). The morphology of the mycelium was observed by a ZEISS EVO SEM (Merlin, Germany) with a $5.00 \mathrm{KV}$ scanning voltage [42].

\subsection{Analytical Assays}

The fungal mycelium pellets were collected by filtration using the qualitative filter paper (diameter $7 \mathrm{~cm}$, Jiaojie, Fushun, China) at the end of the fermentation. The collected solids were freeze-dried for $12 \mathrm{~h}$ after being washed twice by distilled water. The mycelium dry weight (DW) was obtained using the BS224S analytical balance (Sartorius, Germany). A $0.05 \mathrm{~g}$ portion of dried mycelium was mixed into a $10 \mathrm{~mL}$ centrifuge tube containing an equal amount of quartz sand (Acmec Biochemical Co., Ltd., Shanghai, China) and $5 \mathrm{~mL}$ of dichloromethane (Zhiyuan Reagent Co., Ltd., Tianjin, China). The tube was sealed and the hypocrellinses were extracted under ultrasonic irradiation by an AS20500ATH (Tianjin Automatic Science Instrument, China) at $40 \mathrm{KHz}$ for $30 \mathrm{~min}$. Before use, the extraction solution was filtered through a filter membrane $(\varnothing=0.22 \mu \mathrm{m}$, Jinteng Experimental Equipment Co., Ltd., Tianjin, China). An e2695 HPLC system (Waters Corporation, Milford, MA, USA) equipped with a Inertsil ODS-3 column $(5 \mu \mathrm{m}, 4.6 \mathrm{~mm} \times 250 \mathrm{~mm}$, Shimadzu Corporation, Japan) and a PDA detector (2988, Waters Corporation, Milford, MA, USA) was used for the determination of HA content in the extraction solution. The HPLC operating conditions were as follows: mobile phase (methanol/acetic acid, 90/10, v/v); flow rate, $1 \mathrm{~mL} / \mathrm{min}$; column temperature, $30{ }^{\circ} \mathrm{C}$; detector wavelength, $467 \mathrm{~nm}$; injection volume, $10 \mu \mathrm{L}$; sample running time, $12 \mathrm{~min}$. Calculation of the HA content in mycelia, HA conversion yield, and HA yield were according to Equations (1)-(3), respectively.

$\begin{gathered}\mathrm{HA} \text { content in mycelia } \\ (\mathrm{mg} \text { g biomass })\end{gathered}=\frac{\text { HA content in the extract }(\mathrm{mg} / \mathrm{mL}) \times \text { extraction volume }(5 \mathrm{~mL})}{\text { dry weight of mycelia } 0.05 \mathrm{~g}}$ 
$\begin{aligned} & \text { HA conversion yield } \\ & (\mathrm{mg} / \mathrm{g} \text { carbon source })\end{aligned}=\frac{\text { HA content in mycelia }(\mathrm{mg} / \mathrm{g} \text { biomass }) \times \text { mycelium biomass }(\mathrm{g} \text { DW } / \mathrm{L})}{\text { dosage of carbon source }(10 \mathrm{~g})}$,

$\underset{(\mathrm{mg} \mathrm{L})}{\mathrm{HA} \text { yield }}=\frac{\text { HA content in mycelia }(\mathrm{mg} / \mathrm{g} \text { biomass }) \times \text { mycelium biomass }(\mathrm{g} \text { DW/L })}{\text { volume of fermentation broth }(0.05 \mathrm{~L})}$

\subsection{Statistical Analysis}

All results were reported as mean value \pm standard deviation $(n=3)$. Kruskal-Wallis method was used for nonparametric one-way analysis of variance. The analysis was performed using an SPSS Statistics 20 (IBM Corporation, Armonk, NY, USA) program with a significance level of 0.05 and 0.01 .

\section{Results and Discussion}

3.1. The HA Yields by Co-Culture of S. bambusicola (GDMCC 60438) with Different Endophytic Fungi

As shown in Table 1, the endophytic fungi had a distinct effect on the growth of the mycelium biomass in the co-culture system. Among all the strains, the AF-4, AF-5, AF-7, BF-1, BF-3, BF-5 BF-9 showed a significant positive effect on both the mycelium biomass $(p<0.05)$ and the HA yield $(p<0.01)$. After the co-culture of the AF- 5 strain and the S. bambusicola (GDMCC 60438), the HA content in the mycelia and HA yield reached $40.5 \mathrm{mg} / \mathrm{g}$ and $332.92 \mathrm{mg} / \mathrm{L}$, which was about 2.1 times and 2.8 times the control, respectively. In addition, the AF-2 strain showed a strong inhibition effect on the HA synthesis and growth of the mycelia. The biomass and HA yield had a decline of $26.02 \%$ and $68.62 \%$, respectively. Although the AF-4 or BF-5 strains had no remarkable effect on the mycelium growth of the S. bambusicola (GDMCC 60438), the HA contents in the mycelium were increased by $66.71 \%$ and $54.18 \%$, respectively.

Table 1. Effect of different endophyte co-culture with S. bambusicola (GDMCC 60438) on the biomass and HA productivity.

\begin{tabular}{ccccc}
\hline Strain Number & $\begin{array}{c}* \text { Mycelium Biomass } \\
\text { (g DW/L) }\end{array}$ & $\begin{array}{c}* * \text { HA Content in Mycelium } \\
\text { (mg/g Biomass) }\end{array}$ & $\begin{array}{c}* * \text { HA Conversion Yield } \\
\text { (mg/g Carbon Source) }\end{array}$ & $\begin{array}{c}* * \text { HA Production } \\
\text { (mg/L) }\end{array}$ \\
\hline Control & $6.24 \pm 0.19$ & $18.99 \pm 1.36$ & $11.84 \pm 0.65$ & $118.39 \pm 6.5$ \\
AF-1 & $5.39 \pm 1.31$ & $19.79 \pm 1.34$ & $10.54 \pm 1.85$ & $114.60 \pm 13.46$ \\
AF-2 & $4.58 \pm 0.34$ & $8.12 \pm 1.07$ & $3.72 \pm 0.54$ & $37.15 \pm 5.38$ \\
AF-3 & $6.75 \pm 1.67$ & $11.85 \pm 0.6$ & $7.93 \pm 1.57$ & $79.34 \pm 15.74$ \\
AF-4 & $6.38 \pm 0.57$ & $31.69 \pm 4.18$ & $20.10 \pm 0.88$ & $201.02 \pm 8.76$ \\
AF-5 & $8.23 \pm 0.61$ & $40.5 \pm 1.4$ & $33.19 \pm 1.31$ & $332.92 \pm 13.09$ \\
AF-6 & $8.91 \pm 0.49$ & $9.6 \pm 0.53$ & $8.54 \pm 0.04$ & $85.4 \pm 0.36$ \\
AF-7 & $10.53 \pm 0.52$ & $22.92 \pm 1.35$ & $24.10 \pm 0.23$ & $240.87 \pm 2.26$ \\
BF-1 & $6.22 \pm 0.91$ & $33.17 \pm 2.73$ & $20.51 \pm 1.3$ & $205.07 \pm 13.04$ \\
BF-2 & $9.88 \pm 1.74$ & $10.72 \pm 0.67$ & $25.2 \pm 0.92$ & $105.14 \pm 12.46$ \\
BF-3 & $8.07 \pm 0.69$ & $31.29 \pm 1.55$ & $10.88 \pm 0.36$ & $251.95 \pm 9.17$ \\
BF-4 & $8.71 \pm 1.12$ & $11.71 \pm 0.4$ & $17.33 \pm 0.33$ & $108.79 \pm 3.58$ \\
BF-5 & $5.93 \pm 0.13$ & $29.25 \pm 1.19$ & $21.31 \pm 0.32$ & $173.35 \pm 3.34$ \\
BF-6 & $6.95 \pm 0.33$ & $28.11 \pm 0.69$ & $20.67 \pm 1.06$ & $195.19 \pm 9.14$ \\
BF-7 & $9.09 \pm 0.04$ & $23.45 \pm 0.25$ & $17.52 \pm 0.75$ & $213.13 \pm 3.23$ \\
BF-8 & $8.08 \pm 0.32$ & $25.43 \pm 0.06$ & $8.4 \pm 0.73$ & $206.72 \pm 10.65$ \\
BF-9 & $7.29 \pm 0.47$ & $24.11 \pm 2.577$ & $175.20 \pm 7.48$ \\
BF-10 & $6.51 \pm 0.27$ & $12.89 \pm 0.62$ & $85.96 \pm 7.27$ \\
\hline
\end{tabular}

Values shown represent the averages of triplicate samples (mean value \pm standard deviation). Levels for significance of differences ${ }^{*} p<0.05,{ }^{* *} p<0.01$. 
3.2. Molecular Identification and the Culture Features of the Endophytic AF-5 Strain with the S. bambusicola (GDMCC 60438)

A 609-bp ITS DNA fragment of the AF-5 strain was obtained. Blast analysis showed that the sequence was most homologous with Arthrinium arundinis (MK461045.1) and Arthrinium arundinis (MK460910.1). The AF-5 strain should belong to the Arthrinium species due to their close evolutionary distance in the phylogenetic tree (Figure 2). The AF-5 strain was recognized as Arthinium sp. AF-5.

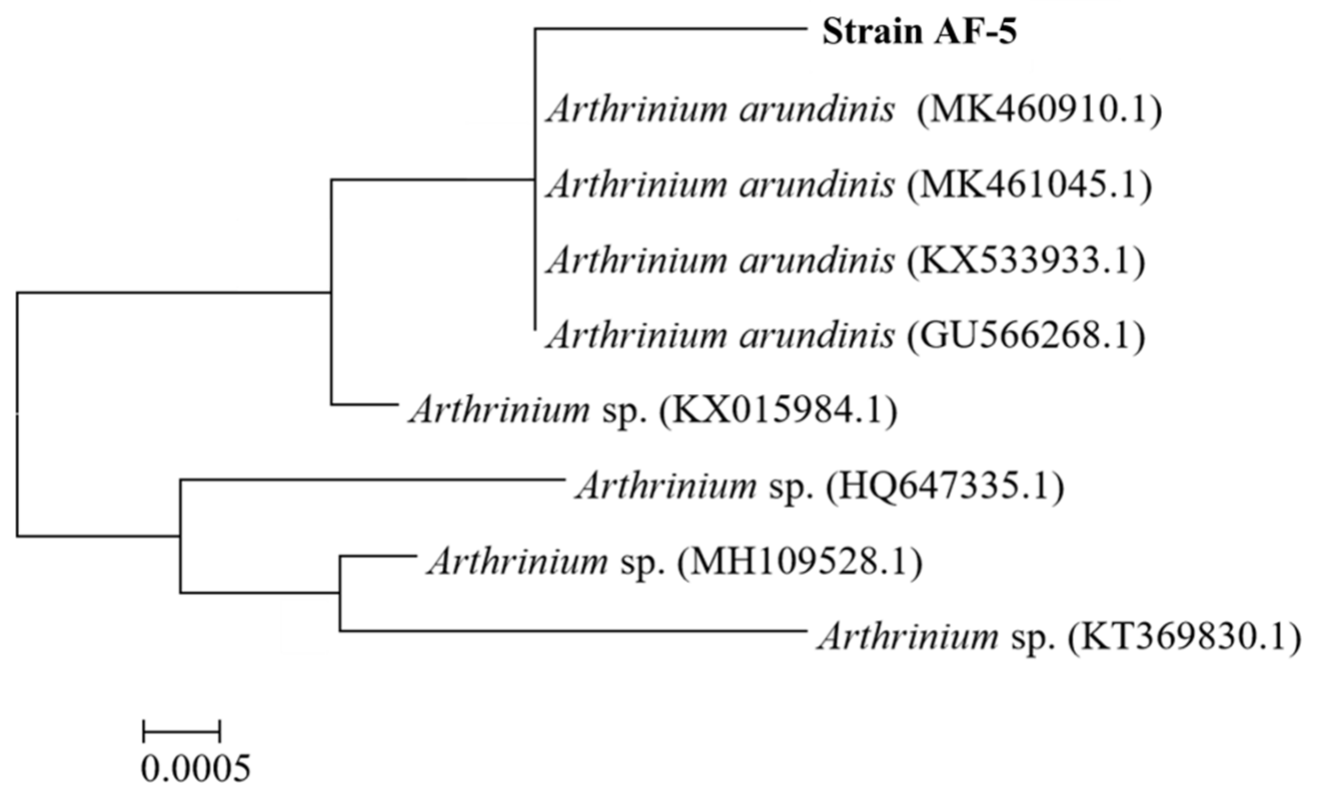

Figure 2. Phylogenetic tree of the strain AF-5 based on the ITS sequences.

On the PDA medium, the S. bambusicola (GDMCC 60438) colony appeared bright red in the middle, but a concentric annular yellow-brown circle appeared on the reverse side of the medium (Figure 3(a1,a2)). When Arthinium sp. AF-5 was inoculated on the PDA medium at $28^{\circ} \mathrm{C}$, the fungal colony could grow to $40 \mathrm{~mm}$ in diameter and cover the whole medium on days 7-10 with white filaments (Figure 3(b1,b2)). When the S. bambusicola (GDMCC 60438) and AF-5 strains were co-cultured together on the PDA medium for 7 days, the contacting edge of the two fungal colonies was in dark red from the middle (Figure 3(c1,c2)). It was revealed that the AF-5 strain could coexist well with $S$. bambusicola (GDMCC 60438) and promote its HA production. Moreover, the growth rate of the AF-5 was higher than that of the S. bambusicola (GDMCC 60438), with a larger AF-5 colony on the PDA medium. To avoid the competition at the early stage, it was necessary to conduct the separated cultivation of the two stains before the co-cultivation during the submerged fermentation.

After the independent cultivation of the S. bambusicola (GDMCC 60438) (Figure 4(a1)) and the Arthinium sp. AF-5 in the PDB medium for $60 \mathrm{~h}$ (Figure 4(b1)), the mycelia of the Arthinium sp. AF-5, which grew more rapidly, adhered and aggregated into about $10 \mathrm{~mm}$ blocks, while the $S$. bambusicola (GDMCC 60438) formed a relatively tiny mycelium pellet with a diameter of about $1 \mathrm{~mm}$. There was no noticeable color change in the mycelia of either of the strains. Figure $4(\mathrm{a} 2, \mathrm{~b} 2)$ shows the morphology of the two strains after being cultured in the fermentation medium for $72 \mathrm{~h}$. The results show that the color of the fermentation broth had a slight change when the strain AF-5 was cultured alone, indicating that no pigment was produced. After inoculating the S. bambusicola (GDMCC 60438) in the fermentation substrate and cultivating for $24 \mathrm{~h}$, the mycelia of the Arthinium sp. AF-5 were added to start the co-culture for another $48 \mathrm{~h}$. Due to the intensive accumulation of HA in the mycelium, the pellet of the co-culture turned dark red and even black (Figure 4c), while the pellet of the S. bambusicola (GDMCC 60438) culture without AF-5 turned to bright red (Figure 4(a2)). 


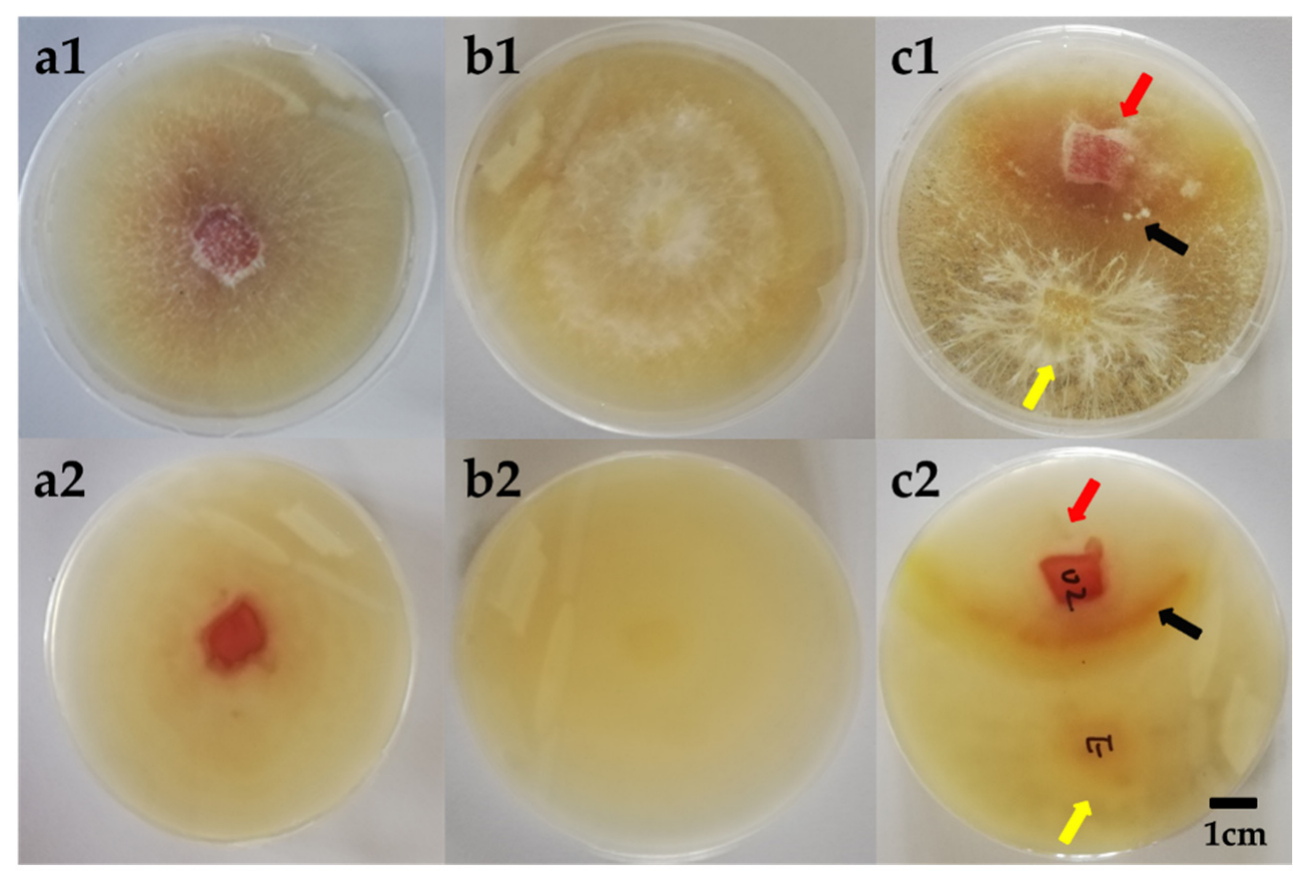

Figure 3. Growth of the mycelia of the S. bambusicola (GDMCC 60438) and the Arthinium sp. AF-5. (a1). Top side of S. bambusicola (GDMCC 60438) plate; (a2). Reverse side of S. bambusicola (GDMCC 60438) plate; (b1). Top side of strain AF-5 plate; (b2). Reverse side of strain AF-5 plate; (c1). Top side of fungus-fungus resistance plate; (c2). Reverse side of fungus-fungus resistance plate. The red arrow points to S. bambusicola (GDMCC 60438), the yellow arrow points to strain AF-5, and the black arrow points to the junction of the two species.

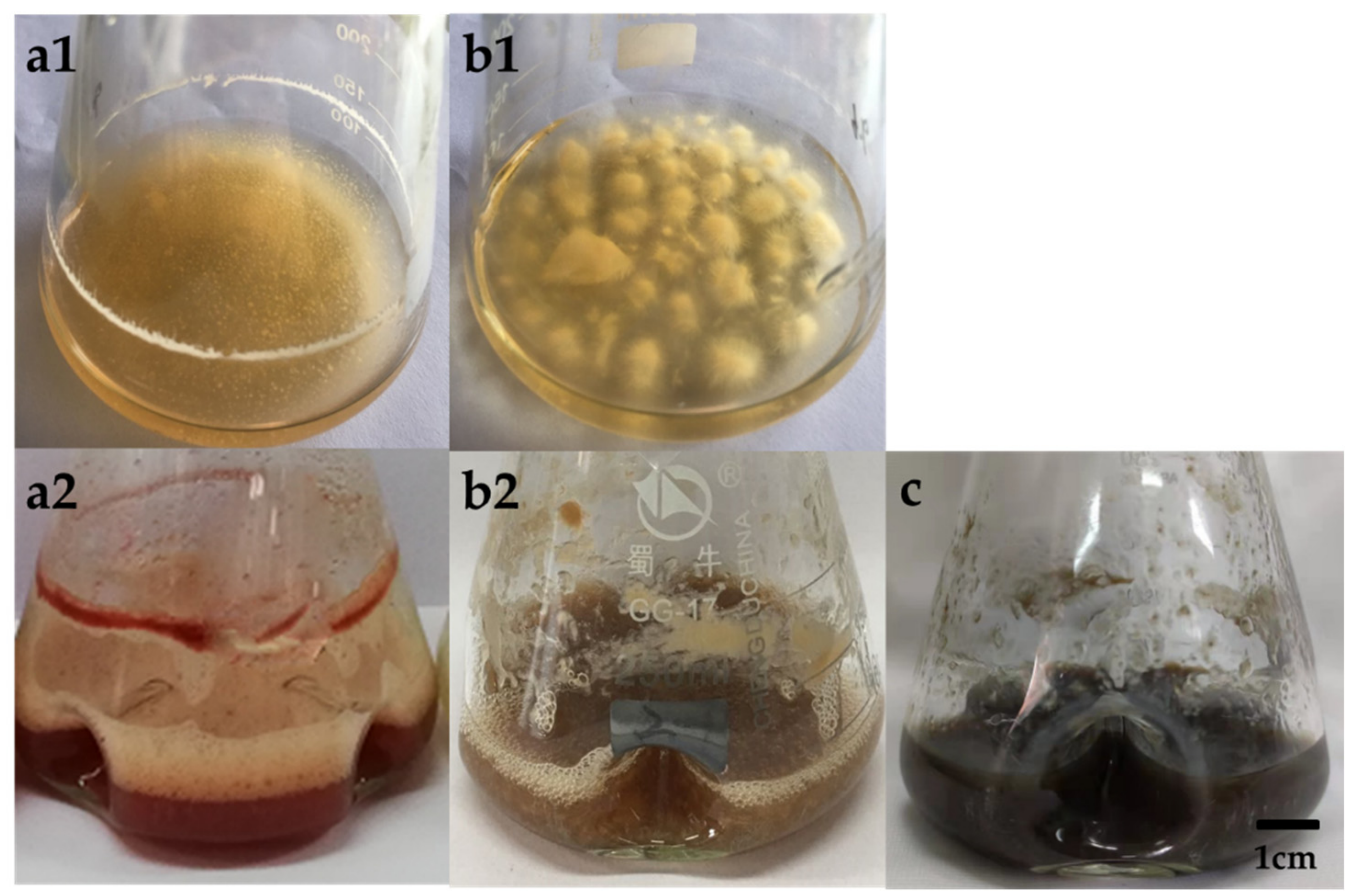

Figure 4. The culture of S. bambusicola (GDMCC 60438) and the Arthinium sp. AF-5. (a1). Seed of the S. bambusicola (GDMCC 60438); (a2). Broth of the S. bambusicola (GDMCC 60438) after a 72-h fermentation; (b1). Seed of the Arthinium sp. AF-5; (b2). Broth of the Arthinium sp. AF-5 after a 72-h fermentation; (c). broth of the co-culture of S. bambusicola (GDMCC 60438) and the Arthinium sp. AF-5 after a 60-h fermentation (the Arthinium sp. AF-5 was added at the $12 \mathrm{~h}$ mark). 


\subsection{Effect of Different Types of the AF-5 Inoculums on the HA Yields}

To determine the effect of the different inoculums on the HA yields, the FP, FS, and FFM of Arthrinium sp. AF-5 were prepared and submitted to the co-cultivation with the S. bambusicola (GDMCC 60438). After the HA fermentation, the mycelium biomass and the HA content of the culture with the FFM were significantly increased compared to those with the FS and FP (Figure 5a). The addition of FFM could effectively stimulate the biosynthesis of HA by the S. bambusicola (GDMCC 60438). Compared with the regular fermentation by the S. bambusicola (GDMCC 60438), the HA conversion yield increased from $14.23 \mathrm{mg} / \mathrm{g}$ carbon source to $24.77 \mathrm{mg} / \mathrm{g}$ carbon source with an increased rate of $74.07 \%$ (Figure $5 b$ ).
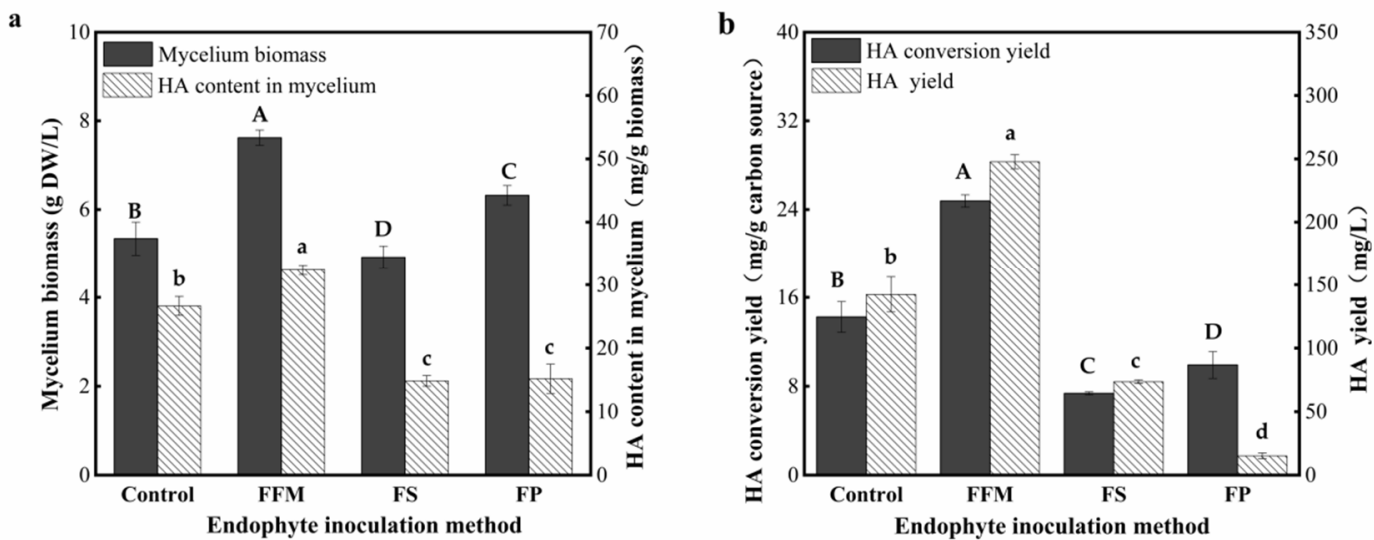

Figure 5. Effects of Arthrinium sp. AF-5 inoculation methods on (a). mycelium biomass and the HA content in mycelium; (b). HA conversion yield and HA yield. Different letters indicated that data were significantly different $(p<0.05)$, and comparisons were made between columns of the same color, the significance between a set of data is marked uniformly in uppercase letters or uniformly in lowercase letters.

It was considered that the polysaccharides, peptides, and glycoproteins derived from microorganisms and plant cells were the most commonly used elicitors for promoting the production of fungal secondary metabolites $[43,44]$. For example, the addition of protein elicitor PB90 isolated from Pasteurella pestis during the liquid fermentation of S. bambusicola could promote the synthesis of hypocrellins and increase the accumulation of phenolic compounds [45]. The induction of elicitors to producing strains is affected by the type, addition dosage, and additional time of elicitors [46]. Du et al. found that the mixed culture of Phoma sp. BZJ6 and S. bambusicola could increase the laccase yield by up to 9.18 times that of the pure culture and enhance the synthesis of total phenols and flavonoids, but it led to a decrease in the biomass [47]. In another work, they introduced bacteria to the S. bambusicola culture and found that they had no significant effect on the growth of the biomass but could increase the hypocrellin yield. The effects on the improvement of the hypocrellin yield were different depending on the media [48]. In this study, the addition of FP could only increase the mycelium biomass rather than the HA yields. It was similar to the report that crude polysaccharides from bacteria had no significant effect on the accumulation of hypocrellins by the Shiraia sp. S9 [45]. It was interesting that the filtrate of the Arthinium sp. AF-5 broth inhibited the growth of S. bambusicola. The inhibition may likely be caused by the defense response against the metabolism molecules in the aqueous phase $[43,49]$.

\subsection{Effect of Introducing Time of the AF-5 Strain on the HA Yield}

The results showed that the biomass, HA content in the mycelium, HA conversion yield, and HA yield were significantly improved when the AF-5 strain was introduced at 12,24 , and $36 \mathrm{~h}$ of the fermentation (Figure 6). Adding the Arthinium sp. AF-5 at the early or late stage of the fermentation led to no remarkable increase in the HA yield. It was indicated that the promotion effect of AF- 5 on the HA yield could depend on the 
metabolism status of S. bambusicola (GDMCC 60438). When adding the Arthinium sp. AF-5 at $12 \mathrm{~h}$, the biomass and HA conversion yield of S. bambusicola (GDMCC 60438) reached $7.28 \mathrm{~g}$ DW/L and $32.8 \mathrm{mg} / \mathrm{g}$ carbon source, which increased by $16.6 \%$ and $177 \%$ compared with the control, respectively.

a

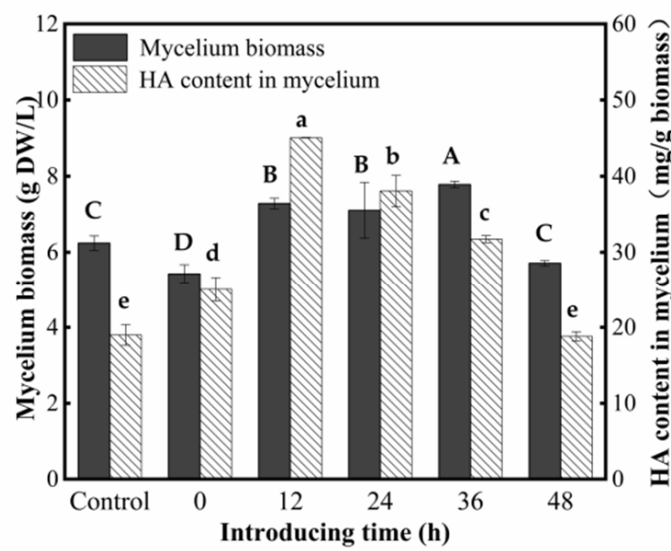

b

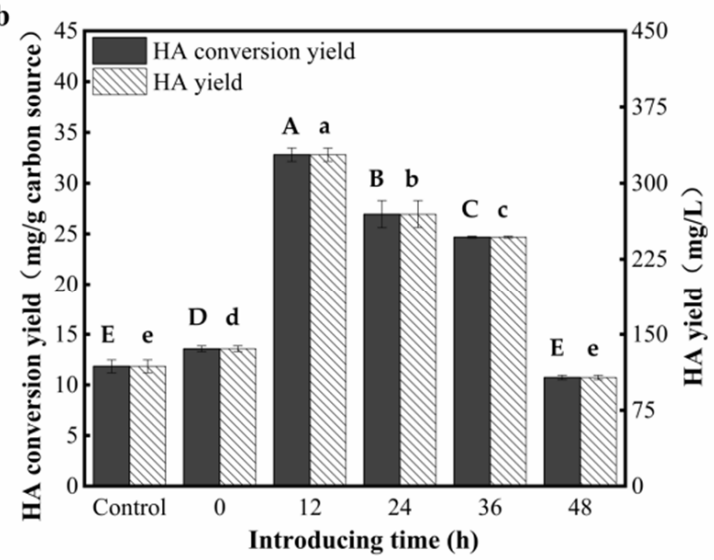

Figure 6. Effects of introducing time of Arthrinium sp. AF-5 on (a). the mycelium biomass and HA content in mycelium; (b). HA conversion yield and HA yield. Different letters indicated that data were significantly different $(p<0.05)$, and comparisons were made between columns of the same color, the significance between a set of data is marked uniformly in uppercase letters or uniformly in lowercase letters.

\subsection{Effect of Dosage of the AF-5 Strain on the HA Yield}

To determine the optimal content of the Arthrinium sp. AF- 5 for HA production in the co-culture system, dosages of $1 \mathrm{~g}(0.02 \mathrm{~g} \mathrm{FW} / \mathrm{mL}), 3 \mathrm{~g}(0.06 \mathrm{~g} \mathrm{FW} / \mathrm{mL}), 5 \mathrm{~g}(0.1 \mathrm{~g} \mathrm{FW} / \mathrm{mL})$, and $7 \mathrm{~g}(0.14 \mathrm{~g} \mathrm{FW} / \mathrm{mL})$ of the Arthrinium sp. AF-5 were added into the pure culture of the S. bambusicola at $12 \mathrm{~h}$. Pure culture of the S. bambusicola without the Arthrinium sp. AF-5 was set as the control. As shown in Figure 7a,b, the increasing dosage of AF-5 gradually promoted the growth of the co-cultured biomass. When the content of the Arthrinium sp. AF-5 reached $0.14 \mathrm{~g} \mathrm{FW} / \mathrm{mL}$, the highest co-cultured biomass of $10.48 \mathrm{~g} \mathrm{DW} / \mathrm{L}$ could be achieved, which was $67.9 \%$ higher than the control. It was indicated that the accumulation of the HA in the mycelia reached the highest level of $55.43 \mathrm{mg} / \mathrm{g}$ when the dosage of the Arthrinium sp. AF-5 was $0.06 \mathrm{~g}$ FW/mL. An over-inoculation of the Arthrinium sp. AF- 5 could have a significantly negative effect on both the HA conversion yield and the production of HA. The highest HA conversion yield of $44.74 \mathrm{mg} / \mathrm{g}$ carbon source could be achieved when the initial content of the Arthrinium sp. AF-5 was $0.06 \mathrm{~g} \mathrm{FW/mL}$.

a

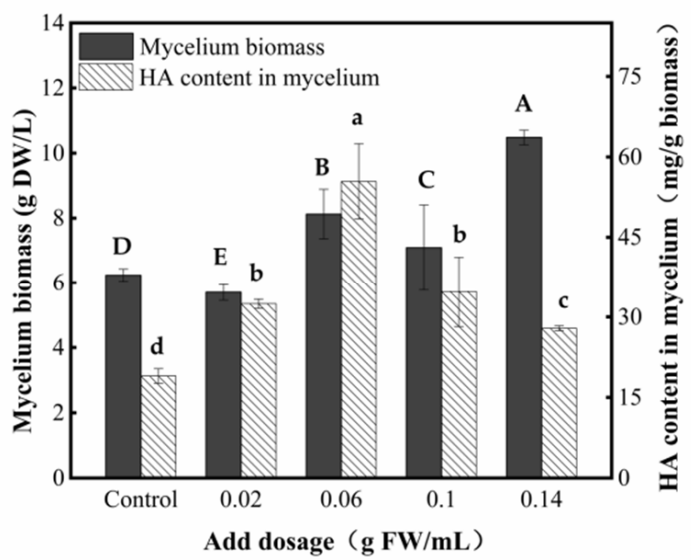

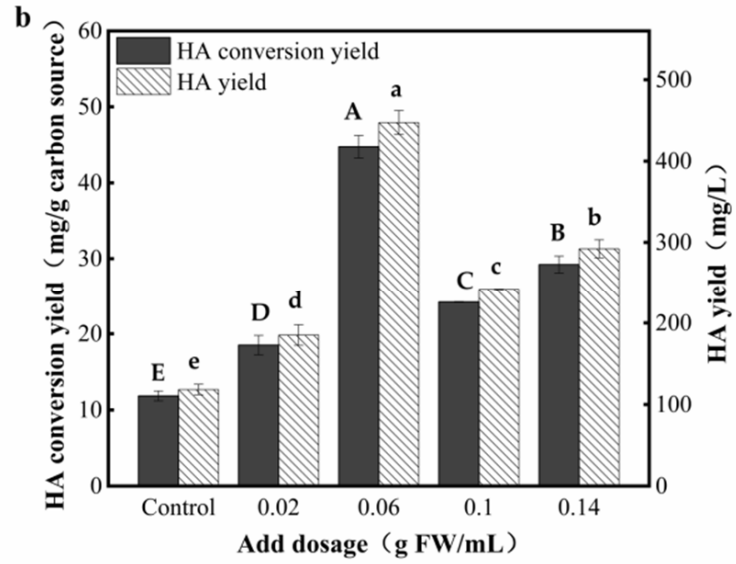

Figure 7. Effects of Arthrinium sp. AF-5 addition dosage on (a). the mycelium biomass and HA content in mycelium; (b). HA conversion yield and HA yield. Different letters indicated that data were significantly different $(p<0.05)$, and comparisons were made between columns of the same color, the significance between a set of data is marked uniformly in uppercase letters or uniformly in lowercase letters. 


\subsection{Effect of the Co-Culture Time on the HA Yield}

The effect of the co-culture time on the HA yield was studied with $0.06 \mathrm{~g} \mathrm{FW} / \mathrm{mL}$ of the Arthrinium sp. AF- 5 co-cultured in the broth of the pure culture of the S. bambusicola. Along with the increase of the co-culture time from $24 \mathrm{~h}$ to $96 \mathrm{~h}$, the mycelium biomass gradually increased from $3.83 \mathrm{~g}$ DW/L to $8.41 \mathrm{~g}$ DW/L (Figure 8a). After an 84-h co-cultivation, the mycelium biomass reached $8.28 \mathrm{~g}$ DW $/ \mathrm{L}, 50 \%$ higher than that of the control group. The HA content in the mycelium, the HA conversion yield, and the HA yield reached $80.68 \mathrm{mg} / \mathrm{g}$, $66.75 \mathrm{mg} / \mathrm{g}$ carbon source, and $667.47 \mathrm{mg} / \mathrm{L}$, respectively (Figure $8 \mathrm{~b}-\mathrm{d}$ ).

a
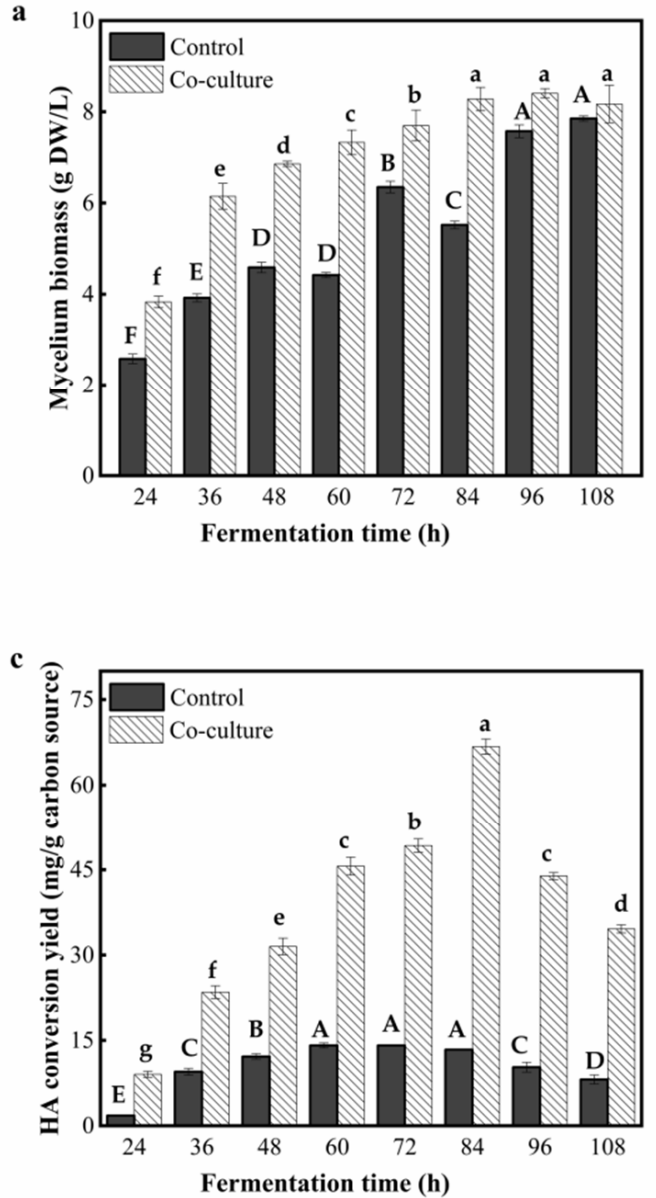

b

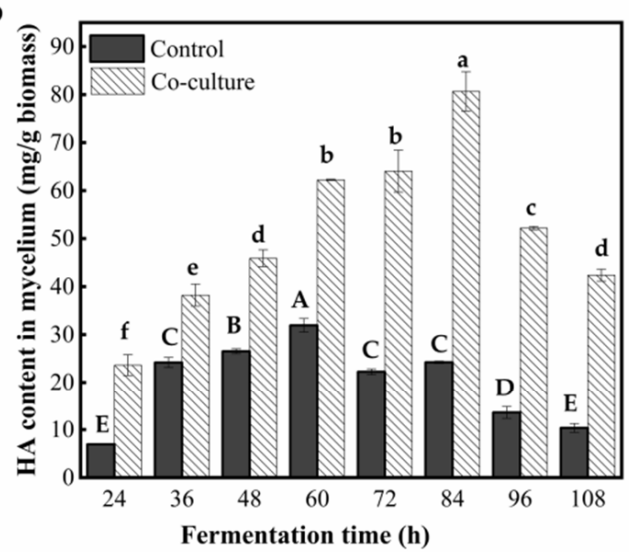

d

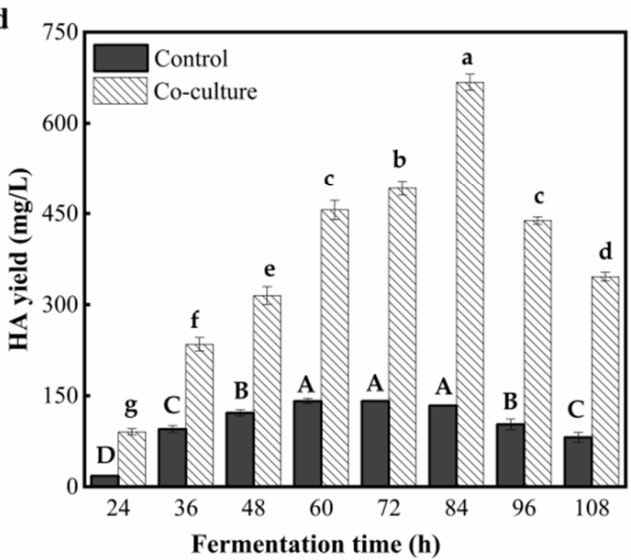

Figure 8. The variation tendency of (a). mycelium biomass, (b). HA content in mycelium, (c). HA conversion yield, and (d). HA yield in the co-culture system. Different letters indicated that data were significantly different $(p<0.05)$, and comparisons were made between columns of the same color, the significance between a set of data is marked uniformly in uppercase letters or uniformly in lowercase letters.

\subsection{Morphological Observation of the Mycelium Pellets during the Co-Culture}

The development of the mycelial pellets during the co-culture was observed under the microscope. As shown in Figure 9, both the mycelial pellets of the pure culture of S. bambusicola and the co-culture system gradually could turn to a dark color with the extension of the cultivation time. However, the pellets could maintain the intact globosity structure but shrink obviously at the end of fermentation. In the beginning, the average diameters of the mycelial pellets of the pure culture and the co-culture gradually reduced to $3.31( \pm 0.05) \mathrm{mm}$ and $2.50( \pm 0.07) \mathrm{mm}$, respectively. After $36 \mathrm{~h}$, the change in the size of the mycelial pellet was almost stable in the control group, but the development of the pellet size continued in the co-culture system. In the late stage of the fermentation, the size of the mycelium pellets in the pure culture and the co-culture systems decreased by $26.44 \%$ and $44.44 \%$, respectively. It was revealed that the time period between $24 \mathrm{~h}$ and $48 \mathrm{~h}$ could be the key stage for mycelium growth and HA accumulation. The change in the 
mycelial pellets might be related to the HA synthesis, which was similar to the result of the co-culture of Shiraia sp. S9 with bacteria [50].

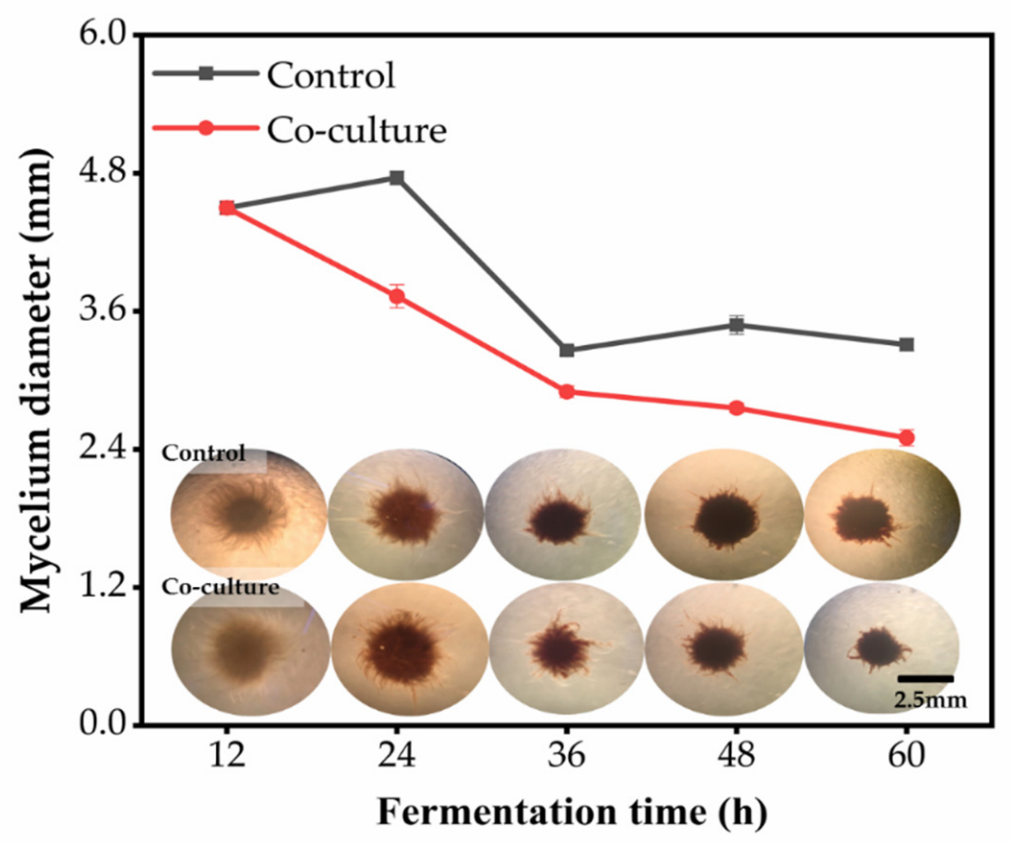

Figure 9. Change in the morphology and size of the mycelium pellets during the fermentation.

SEM observation showed that the Arthrinium sp. AF-5 had flat, horizontal segmentation mycelia with a diameter of $2.20( \pm 0.13) \mu \mathrm{m}$ (Figure $10(\mathrm{c} 1, \mathrm{c} 2))$. The diameter of the $S$. bambusicola (GDMCC 60438) mycelia was about $1.82( \pm 0.11) \mu \mathrm{m}$ (Figure 10(a1,a2)) with a branched-tubular structure. The mycelia of the Arthrinium sp. AF-5 and S. bambusicola (GDMCC 60438) contracted and intertwined with each other with an interwoven pattern in the co-culture system (Figure 10(b1,b2)).

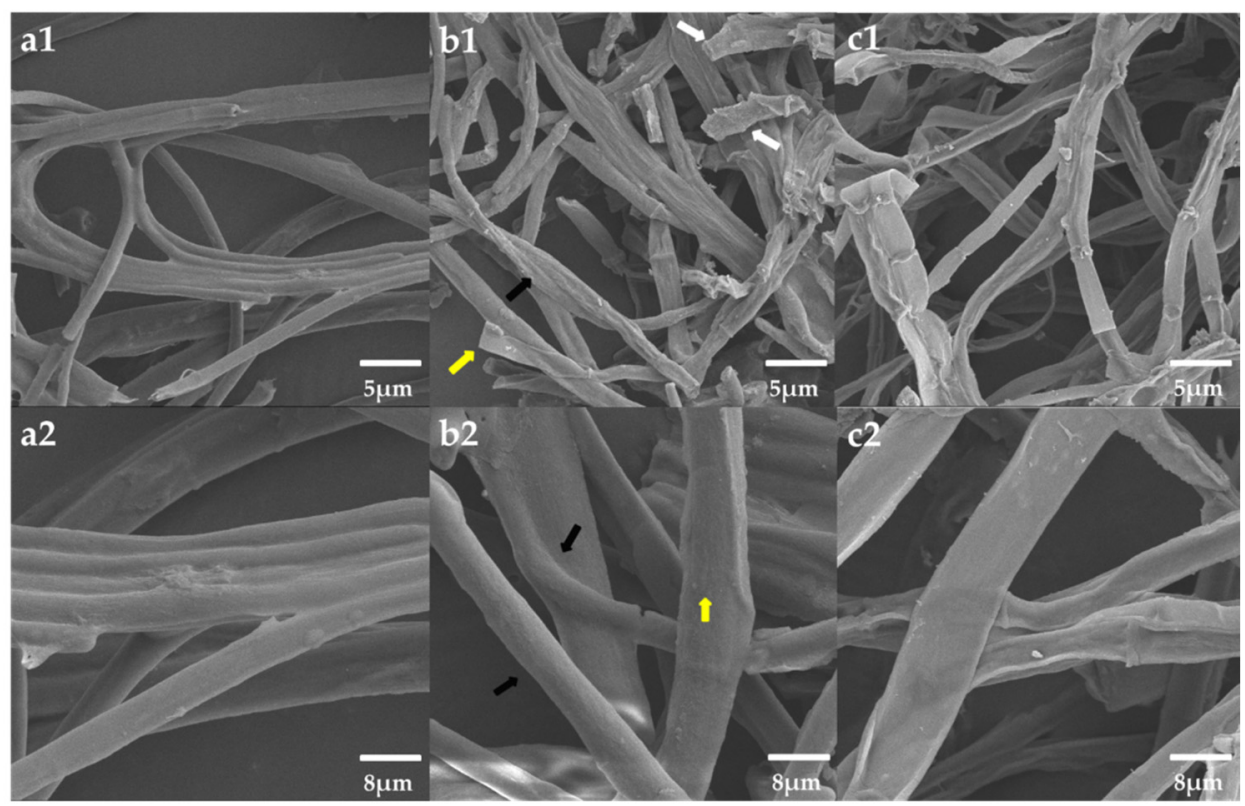

Figure 10. SEM image of mycelium, S. bambusicola (GDMCC 60438) (a1,a2), co-culture (b1,b2), and Arthrinium sp. AF-5 (c1,c2). The black arrow represents the mycelia of the S. bambusicola (GDMCC 60438), the yellow arrow represents the mycelia of the Arthrinium sp. AF-5, and the white arrow represents the damaged structure of the S. bambusicola (GDMCC 60438) mycelia. 
In the co-culture system, the increased HA yield was generally contributed by the accelerated HA accumulation in the mycelia rather than the stimulation of the growth of the mycelium biomass. RNA sequencing and the transcriptomic analysis confirmed that the expression of the polyketide synthase and ATP-binding cassette of S. bambusicola was up-regulated during the co-culture of $S$. bambusicola with bacteria, suggesting the endophytic fungi may promote the metabolism of polyketone compounds, the precursor of HA [24]. It was speculated that the regulatory mechanisms of the Arthrinium sp. AF-5 promoting the HA accumulation in S. bambusicola (GDMCC 60438) could rely on regulating the metabolism enzyme system through interaction communication [37].

\subsection{Effect of the $\mathrm{H}_{2} \mathrm{O}_{2}$ Addtives on the $\mathrm{HA}$ Yield during the Co-Culture}

Considering that S. bambusicola (GDMCC 60438) and the Arthrinium sp. AF-5 were oxygen-consuming fungi, the increase in the inoculation dosage in the co-culture system will accelerate the increase in the oxygen demand. Except for providing oxygen, it was reported that $\mathrm{H}_{2} \mathrm{O}_{2}$ may mediate the signaling pathways for $\mathrm{HA}$ accumulation [51]. In this study, the $\mathrm{H}_{2} \mathrm{O}_{2}$ was introduced in the co-culture system, and its effect on the HA yield was investigated.

The oxygen metabolism can be balanced by adding an exogenous oxidant or reductant in the fermentation broth [52]. Adding $\mathrm{H}_{2} \mathrm{O}_{2}$ in the co-culture system could promote the growth of the mycelium biomass and the accumulation of the HA in the mycelia. For example, when adding $0.5 \mathrm{mM} \mathrm{H}_{2} \mathrm{O}_{2}$, the $\mathrm{HA}$ yield increased slightly to $51.32 \mathrm{mg} / \mathrm{g}$ carbon source, $18.31 \%$ higher than that of the control (Figure 11). The adding of $\mathrm{H}_{2} \mathrm{O}_{2}$ could be helpful in further promoting the HA yields, but the dosage should be controlled at a proper level.
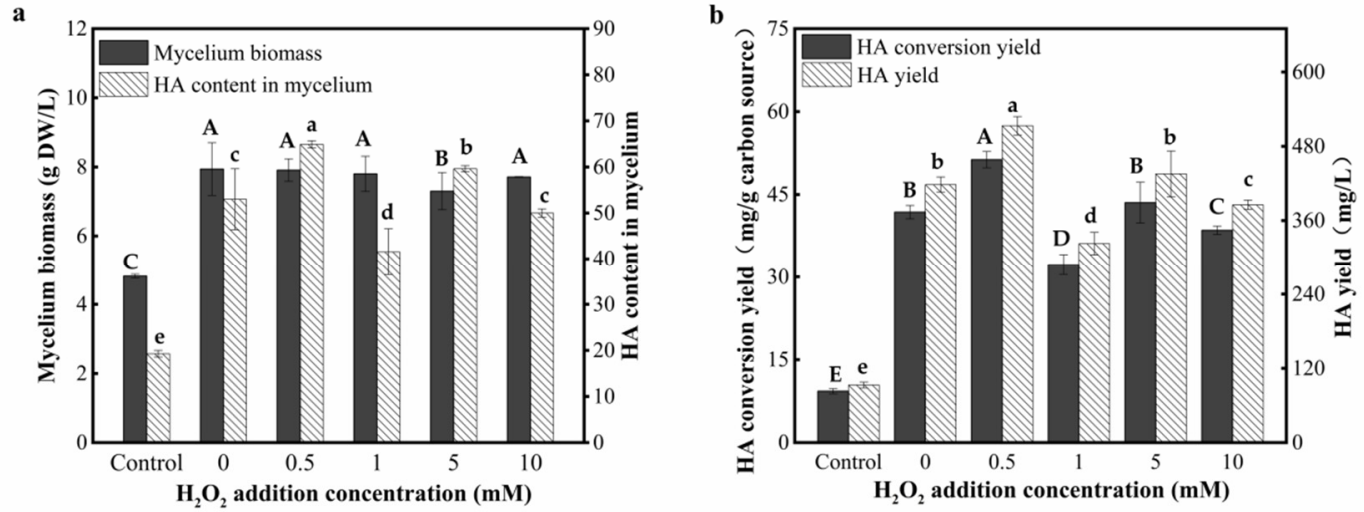

Figure 11. Effect of exogenous $\mathrm{H}_{2} \mathrm{O}_{2}$ on mycelium biomass and $\mathrm{HA}$ yield in the co-culture system. (a). mycelium biomass and HA content in mycelium; (b). HA conversion yield and HA yield. Different letters indicated that data were significantly different $(p<0.05)$, and comparisons were made between columns of the same color, the significance between a set of data is marked uniformly in uppercase letters or uniformly in lowercase letters.

The co-culture of S. bambusicola (GDMCC 60438) with the Arthrinium sp. AF-5 was an effective strategy to promote the HA yields through the submerged fermentation. With an in-depth understanding of the possible role and mechanism of the endophytic fungi in the regulation of the HA production, more techniques, e.g., feeding of precursor, nutrition, or even signal molecules, could be developed and applied to the biosynthesis of the HA in the future. Additionally, the biomass of the co-culture was higher than the total of the two fungal biomasses obtained from separate cultivation. However, it was difficult to determine the biomass of S. bambusicola (GDMCC 60438) alone as the mycelia of the two strains entangled together in the co-culture system. The effect of the co-culture on the individual fungal biomass growth could be further investigated through the analysis of the anatomical structure of the pellets using the fluorescent staining method. 


\section{Conclusions}

An endophytic fungi Arthrinium sp. AF-5 was isolated to enhance the HA production of strain S. bambusicola (GDMCC 60438). The optimal form of inoculation (FFM), the optimal inoculation time $(12 \mathrm{~h})$, the optimal addition amount $(0.06 \mathrm{~g} \mathrm{FW} / \mathrm{mL})$, and the optimal fermentation time $(84 \mathrm{~h})$ were determined for the co-culture. The co-cultivation of the S. bambusicola (GDMCC 60438) with the endophytic Arthrinium sp. AF-5 strain could significantly promote the HA yield, with the highest HA production of $667.47 \mathrm{mg} / \mathrm{L}$ and the highest HA conversion yield of $66.75 \mathrm{mg} / \mathrm{g}$. During the co-cultivation, the mycelium biomass was increased by $11.01 \%$, and the accumulation of the HA in the mycelia was promoted by 3.84 times, reaching $52.19 \mathrm{mg} / \mathrm{g}$. The enhanced HA production could be related to the contact communication between the two strains by intertwined hyphae in the mycelial pellets. In addition, proper amounts of $\mathrm{H}_{2} \mathrm{O}_{2}$ may supplement oxygen in the co-culture system for further increasing HA production. However, an additional investigation would be necessary to understand the molecular mechanisms by which the co-culture works according to evidence.

Author Contributions: Conceptualization, X.T.; methodology, M.H.; investigation, X.Y. and Y.W.; resources, X.T.; data curation, M.H.; writing—original draft preparation, X.Y. and Y.W.; writingreview and editing, X.T.; supervision, X.T. and Z.W. All authors have read and agreed to the published version of the manuscript.

Funding: This research received the opening funds of Guangdong Key Laboratory of Fermentation \& Enzyme Engineering, China (2021-6).

Institutional Review Board Statement: Not applicable.

Informed Consent Statement: Not applicable.

Data Availability Statement: Not applicable.

Conflicts of Interest: The authors declare no conflict of interest.

\section{References}

1. Ali, S.M.; Olivo, M. Efficacy of Hypocrellins Pharmacokinetics in Phototherapy. Int. J. Oncol. 2003, 21, 1229-1237. [CrossRef]

2. Cheng, T.F.; Jia, X.M.; Ma, X.H.; Lin, H.P.; Zhao, Y.H. Phylogenetic Study on Shiraia Bambusicola by Rdna Sequence Analyses. J. Basic Microbiol. 2010, 44, 339-350. [CrossRef] [PubMed]

3. Doungporn, M.; Hiroko, K.; Tatsuji, S. Molecular Diversity of Bamboo-Associated Fungi Isolated from Japan. FEMS Microbiol. Lett. 2010, 1, 10-19.

4. Jia, X.M.; Xu, X.H.; Zhuang, B.C.; Lin, H.P. The Progress of Biological Research of Medicinal Fungus Shiraia Bambusicola. Microbiology 2006, 33, 147-150.

5. Ca, I.Y.; Ding, Y.; Tao, G.; Liao, X. Production of 1,5-Dihydroxy-3-Methoxy-7-Methylanthracene-9,10-Dione by Submerged Culture of Shiraia Bambusicola. J. Microbiol. Biotechnol. 2008, 18, 322.

6. Kishi, T.; Tahara, S.; Taniguchi, N.; Tsuda, M.; Takahashi, S. New Perylenequinones from Shiraia Bambusicola. Planta Med. 1991, 57, 376-379. [CrossRef]

7. Cai, Y.; Wei, Z.; Liao, X.; Ding, Y.; Sun, J. Characterization of Three Extracellular Polysaccharides from Shiraia sp. Super-H168 under Submerged Fermentation. Carbohydr. Polym. 2010, 82, 34-38. [CrossRef]

8. Ali, S.M.; Chee, S.K.; Yik, G. Hypericin and Hypocrellins Induced Apoptosis in Human Mucosal Carcinoma Cells. J. Photochem. Photobiol. B Biol. 2001, 65, 59-73. [CrossRef]

9. Wang, N.; Zhang, Z. Relationship between Photosensitizing Activities and Chemical Structure of Hypocrellins a and B. J. Photochem. Photobiol. B 1992, 14, 207-217.

10. Chaloupka, R.; Sureau, F.; Kocisova, E.; Petrich, J.W. Hypocrellins a Photosensitization Involves an Intracellular Ph Decrease in 3t3 Cells. Photochem. Photobiol. 2010, 68, 44-50. [CrossRef]

11. Hudson, J.; Zhou, J.; Chen, J.; Harris, L.; Yip, L.; Towers, G. Hypocrellins, from Hypocrella Bambuase, Is Phototoxic to Human Immunodeficiency Virus. Photochem. Photobiol. 2010, 60, 253-255. [CrossRef] [PubMed]

12. Zhenjun, D.; Lown, J.W. Hypocrellins and Their Use in Photosensitization. Photochem. Photobiol. 1990, 52, 609-616. [CrossRef] [PubMed]

13. Yang, H.; Xiao, C.; Ma, W.; He, G. The Production of Hypocrellins Colorants by Submerged Cultivation of the Medicinal Fungus Shiraia Bambusicola. Dye. Pigment. 2009, 82, 142-146. [CrossRef] 
14. Lei, X.Y.; Zhang, M.Y.; Ma, Y.J.; Wang, J.W. Transcriptomic Responses Involved in Enhanced Production of Hypocrellins a by Addition of Triton X-100 in Submerged Cultures of Shiraia Bambusicola. J. Ind. Microbiol. Biotechnol. 2017, 44, 1425-1429. [CrossRef] [PubMed]

15. Deng, H.; Liang, W.; Fan, T.P.; Zheng, X.; Cai, Y. Modular Engineering of Shiraia Bambusicola for Hypocrellins Production through an Efficient Crispr System. Int. J. Biol. Macromol. 2020, 165, 796-803. [CrossRef]

16. Bertrand, S.; Bohni, N.; Schnee, S.; Schumpp, O.; Gindro, K.; Wolfender, J.L. Metabolite Induction Via Microorganism Co-Culture: A Potential Way to Enhance Chemical Diversity for Drug Discovery. Biotechnol. Adv. 2014, 32, 1180-1204. [CrossRef]

17. Bérdy, J. Thoughts and Facts About Antibiotics: Where We Are Now and Where We Are Heading. J. Antibiot. 2012, 65, 385-395. [CrossRef]

18. Brakhage, A.A. Regulation of Fungal Secondary Metabolism. Nat. Rev. Microbiol. 2013, 11, 21-32. [CrossRef]

19. Keller, N.P.; Turner, G.; Bennett, J.W. Fungal Secondary Metabolism-from Biochemistry to Genomics. Nat. Rev. Microbiol. 2005, 3, 937-947. [CrossRef]

20. Boruta, T.; Milczarek, I.; Bizukojc, M. Evaluating the Outcomes of Submerged Co-Cultivation: Production of Lovastatin and Other Secondary Metabolites by Aspergillus Terreus in Fungal Co-Cultures. Appl. Microbiol. Biotechnol. 2019, 103, 5593-5605. [CrossRef]

21. Bader, J.; Mast-Gerlach, E.; Popovi, M.K.; Bajpai, R.; Stahl, U. Relevance of Microbial Coculture Fermentations in Biotechnology. J. Appl. Microbiol. 2010, 109, 371-387. [CrossRef] [PubMed]

22. Smid, E.; Lacroix, C. Microbe-Microbe Interactions in Mixed Culture Food Fermentations. Curr. Opin. Biotechnol. 2013, 24, 148-154. [CrossRef] [PubMed]

23. Scherlach, K.; Hertweck, C. Triggering Cryptic Natural Product Biosynthesis in Microorganisms. Org. Biomol. Chem. 2009, 7, 1753-1760. [CrossRef] [PubMed]

24. Chagas, F.O.; Dias, L.G.; Pupo, M.T. A Mixed Culture of Endophytic Fungi Increases Production of Antifungal Polyketides. J. Chem. Ecol. 2013, 39, 1335-1342. [CrossRef]

25. Marmann, A.; Aly, A.; Lin, W.; Wang, B.; Proksch, P. Co-Cultivation-a Powerful Emerging Tool for Enhancing the Chemical Diversity of Microorganisms. Mar. Drugs 2014, 12, 1043-1065. [CrossRef]

26. Brakhage, A.A.; Schroeckh, V. Fungal Secondary Metabolites-Strategies to Activate Silent Gene Clusters. Fungal Genet. Biol. FG B 2011, 48, 15-22. [CrossRef]

27. Chávez, R.; Fierro, F.; García-Rico, R.O.; Vaca, I. Filamentous Fungi from Extreme Environments as a Promising Source of Novel Bioactive Secondary Metabolites. Front. Microbiol. 2015, 6, 903. [CrossRef]

28. Netzker, T.; Fischer, J.; Weber, J.; Mattern, D.J.; König, C.C.; Valiante, V.; Schroeckh, V.; Brakhage, A.A. Microbial Communication Leading to the Activation of Silent Fungal Secondary Metabolite Gene Clusters. Front. Microbiol. 2015, 6, 299. [CrossRef]

29. Brenner, K.; You, L.; Arnold, F.H. Engineering Microbial Consortia: A New Frontier in Synthetic Biology. Trends Biotechnol. 2008, 26, 483-489. [CrossRef]

30. Zuck, K.M.; Shipley, S.; Newman, D.J. Induced Production of N-Formyl Alkaloids from Aspergillus Fumigatus by Co-Culture with Streptomyces Peucetius. J. Nat. Prod. 2011, 74, 1653. [CrossRef]

31. Wang, L.; Wei, W.; Tian, X.; Shi, K.; Wu, Z. Improving Bioactivities of Polyphenol Extracts from Psidium Guajava L. Leaves through Co-Fermentation of Monascus Anka Gim 3.592 and Saccharomyces Cerevisiae Gim 2.139. Ind. Crop. Prod. 2016, 94, 206-215. [CrossRef]

32. Yan, P.-M.; Xue, W.-T.; Tan, S.-S.; Zhang, H.; Chang, X.-H. Effect of Inoculating Lactic Acid Bacteria Starter Cultures on the Nitrite Concentration of Fermenting Chinese Paocai. Food Control 2008, 19, 50-55. [CrossRef]

33. Szambelan, K.; Nowak, J.; Czarnecki, Z. Use of Zymomonas Mobilis and Saccharomyces Cerevisiae Mixed with Kluyveromyces Fragilis for Improved Ethanol Production from Jerusalem Artichoke Tubers. Biotechnol. Lett. 2004, 26, 845-848. [CrossRef]

34. Xie, X.H.; Fan, F.X.; Yuan, X.W.; Liu, N.; Liu, J.S. Isolation of High Performance Bacterial Consortium Ff and Its Decolorization Effects on Reactive Black 5. J. Donghua Univ. (Nat. Sci.) 2013, 39, 802-813.

35. Meyer, V.; Stahl, U. The Influence of Co-Cultivation on Expression of the Antifungal Protein in Aspergillus Giganteus. J. Basic Microbiol. 2003, 43, 68-74. [CrossRef]

36. Ola, A.; Thomy, D.; Lai, D.; Br Tz-Oesterhelt, H.; Proksch, P. Inducing Secondary Metabolite Production by the Endophytic Fungus Fusarium Tricinctum through Coculture with Bacillus Subtilis. J. Nat. Prod. 2013, 76, 2094-2099. [CrossRef] [PubMed]

37. Shin, C.S.; Kim, H.J.; Kim, M.J.; Ju, J.Y. Morphological Change and Enhanced Pigment Production of Monascus When Cocultured with Saccharomyces Cerevisiae or Aspergillus Oryzae. Biotechnol. Bioeng. 2015, 59, 576-581. [CrossRef]

38. Ma, Y.J.; Zheng, L.P.; Wang, J.W. Bacteria Associated with Shiraia Fruiting Bodies Influence Fungal Production of Hypocrellins A. Front. Microbiol. 2019, 10, 2023. [CrossRef]

39. Jian-Feng, L.I.; Chen, L.I.; Liao, L.M. Study on Extraction of Honeysuckle Polysaccharide by Internal Boiling Method. Food Mach. 2016, 19, 155-159.

40. Cubero, O.F.; Crespo, A.; Fatehi, J.; Bridge, P.D. DNA Extraction and Pcr Amplification Method Suitable for Fresh, HerbariumStored, Lichenized, Other Fungi. Plant Syst. Evol. 1999, 216, 243-249. [CrossRef]

41. Liu, X.; Chen, Y.; Wu, L.; Wu, X.; Huang, Y. Optimization of Polysaccharides Extraction from Dictyophora Indusiata and Determination of Its Antioxidant Activity-Sciencedirect. Int. J. Biol. Macromol. 2017, 103, 175-181. [CrossRef]

42. Hu, M.; Cai, Y.; Liao, X.; Hao, Z.; Liu, J. Development of an Hplc Method to Analyze and Prepare Elsinochrome C and Hypocrellins a in the Submerged Fermentation Broth of Shiria sp. Super-H168. Biomed. Chromatogr. 2012, 26, 737-742. [CrossRef] [PubMed] 
43. Wen, W.J.; Wu, J.Y. Effective Elicitors and Process Strategies for Enhancement of Secondary Metabolite Production in Hairy Root Cultures. Adv. Biochem. Eng. Biotechnol. 2013, 134, 55-89.

44. Zhu, L.W.; Zhong, J.J.; Tang, Y.J. Significance of Fungal Elicitors on the Production of Ganoderic Acid and Ganoderma Polysaccharides by the Submerged Culture of Medicinal Mushroom Ganoderma Lucidum. Process Biochem. 2008, 43, 1359-1370. [CrossRef]

45. Ishihara, A.; Nakao, T.; Mashimo, Y.; Murai, M.; Ichimaru, N.; Tanaka, C.; Nakajima, H.; Wakasa, K.; Miyagawa, H. Probing the Role of Tryptophan-Derived Secondary Metabolism in Defense Responses against Bipolaris Oryzae Infection in Rice Leaves by a Suicide Substrate of Tryptophan Decarboxylase. Phytochemistry 2011, 72, 7-13. [CrossRef] [PubMed]

46. Simic, S.G.; Tusevski, O.; Maury, S.; Hano, C.; Delaunay, A.; Chabbert, B.; Lamblin, F.; Laine, E.; Joseph, C.; Hagege, D. Fungal Elicitor-Mediated Enhancement in Phenylpropanoid and Naphtodianthrone Contents of Hypericum Perforatuml. Cell Cultures. Plant Cell Tissue Organ. Cult. 2015, 122, 213-226. [CrossRef]

47. Du, W.; Liang, Z.; Zou, X.; Han, Y.; Liang, J.; Yu, J.; Chen, W.; Wang, Y.; Sun, C. Effects of Microbial Elicitor on Production of Hypocrellins by Shiraia Bambusicola. Folia Microbiol. 2013, 58, 283-289. [CrossRef]

48. Wang, J.W.; Zhang, Z.; Tan, R.X. Stimulation of Arteisinin Production in Artemisia Annua Hairy Roots by the Elicitor from the Endohytic Colletotrichum sp. Biotechnol. Lett. 2001, 23, 857-860. [CrossRef]

49. Wakefield, J.; Hassan, H.M.; Jaspars, M.; Ebel, R.; Rateb, M.E. Dual Induction of New Microbial Secondary Metabolites by Fungal Bacterial Co-Cultivation. Front. Microbiol. 2017, 8, 1284. [CrossRef]

50. Ma, Y.J.; Zheng, L.P.; Wang, J.W. Inducing Perylenequinone Production from a Bambusicolous Fungus Shiraia sp. S9 through Co-Culture with a Fruiting Body-Associated Bacterium Pseudomonas Fulva Sb1. Microb. Cell Factories 2019, 18, 121. [CrossRef]

51. Du, W.; Sun, C.; Wang, J.; Xie, W.; Wang, B.; Liu, X.; Zhang, Y.; Fan, Y. Conditions and Regulation of Mixed Culture to Promote Shiraia Bambusicola and Phoma Sp. Bzj6 for Laccase Production. Sci. Rep. 2017, 7, 17801. [CrossRef] [PubMed]

52. González-Siso, M.I.; García-Leiro, A.; Tarrío, N.; Cerdán, M.E. Sugar Metabolism, Redox Balance and Oxidative Stress Response in the Respiratory Yeast Kluyveromyces Lactis. Microb. Cell Factories 2009, 8, 46. [CrossRef] [PubMed] 